\title{
Prevalence and Impact of Body Physical Changes in HIV Patients Treated with Highly Active Antiretroviral Therapy: Results from a Study on Patient and Physician Perceptions
}

\author{
Esther Cabrero, Ph.D., Laura Griffa, M.D., Ph.D., Angel Burgos, M.D., Ph.D., \\ on behalf of the HIV Body Physical Changes Study Group
}

\begin{abstract}
Patients infected with HIV treated with highly active antiretroviral therapy (HAART) frequently develop body physical changes (BPC) that have an important psychosocial burden. The purpose of this study was to determine the prevalence of BPC observed by HIV-infected patients and their attending physicians and to assess the impact BPC had on daily life. In this epidemiologic multicenter study, patients with HIV infection and their treating physicians filled out parallel questionnaires about their perceptions of specific BPC and their impact on daily activities. A total of 965 patient-physician questionnaires were collected across 98 health centers. Patient's mean age was $43.7 \pm 8.5$ years and $72.6 \%$ were men. Adjusted prevalence of perceived BPC by patients and physicians was 55.1\% (95\% confidence interval [CI]: 52.0-58.1) and 55.2\% (95\% CI: 52.1-58.2), respectively $(p=1.000)$. Overall patient-physician agreement concerning perception of BPC was $83 \%(p<0.0005)$. The most common BPC was lipoatrophy, described by $46.8 \%$ (95\% CI: $43.7-49.8$ ) of patients and $49.4 \%$ (95\% CI: $46.3-52.5)$ of physicians ( $p=0.033)$ followed by lipohypertrophy. No gender differences were observed in the global prevalence of BPC $(p=0.649)$. However, significantly more women reported lipoatrophy of the lower limbs $(p=0.009)$ and buttocks $(p=0.007)$, as well as lipohypertrophy ( $p=0.007)$, than men; $58.2 \%$ (95\% CI: $54.0-62.4)$ patients noted that BPC negatively affected their daily activities. This study reflects the high prevalence of patient and physicianperceived BPC in the HIV population, and the adverse impact on daily life. Physicians should be aware of the psychosocial consequences of BPC in HIV patients in order to improve patient well-being.
\end{abstract}

\section{Introduction}

B EFORE THE ADVENT OF highly active antiretroviral therapy (HAART), patients with HIV infection developed physical manifestations related to the viral infection and AIDS. These symptoms were grouped under the name of wasting syndrome, which involved a progressive loss of lean body mass with preservation of body fat. ${ }^{1,2}$ Patients also developed other changes in appearance associated with the acquisition of opportunistic infections such as herpes simplex, oral candidiasis, hairy leukoplakia and molluscum contagiosum, and rare tumors like Kaposi's sarcoma. ${ }^{3-5}$ These conditions were often used as indicators of advanced disease, and their connection with AIDS was a constant reminder of the fatal and transmissible nature of the disease that these patients were carrying. ${ }^{6,7}$
The situation changed with the introduction of HAART, which markedly reduced opportunistic infections and HIVrelated morbidity and mortality, as well as the outward signs associated with the development of AIDS. ${ }^{8,9}$ On the other hand, the transformation of this fatal disease into a chronic illness led to the emergence of metabolic complications secondary to long-term HAART use. In effect, a clinical syndrome consisting of peripheral lipodystrophy, hyperlipidemia, diabetes, and insulin resistance was described in 1998 in HIV patients receiving at least one protease inhibitor (PI). ${ }^{10}$ Since then, different risk factors, including HIV infection itself, have been identified as risk factors for the development of such syndrome. ${ }^{11-13}$ Noteworthy, the number of studies assessing HAART-associated metabolic disorders has increased steadily, leading to the identification of additional alterations affecting physical appearance. ${ }^{14-16}$ Frequent physical changes

Medical Department, Abbott Laboratories, Madrid, Spain. 
related with HAART include lipodystrophy, a wide range of dermatologic changes, and jaundice. ${ }^{14}$

Lipodystrophy is a disorder characterized by an abnormal distribution of subcutaneous fat, and includes peripheral fat loss (lipoatrophy) in the arms, legs, face and buttocks, and lipohypertrophy (fat accumulation) in the trunk, chest, breasts, neck, or other areas of the body. ${ }^{17,18}$ In addition, lipodystrophy has been associated with other metabolic features, including disturbances in lipid and glucose metabolism, mitochondrial toxicity, and elevated hepatic transaminases. ${ }^{17,19}$ Although the prevalence of lipodystrophy varies widely, from around $7 \%$ to $84 \%{ }^{20}$ depending on the diagnostic criteria used, the overall prevalence of at least one physical change is approximately $50 \%{ }^{21,22}$ The etiology of lipodystrophy is multifactorial, involving many overlapping risk factors related to the duration of HIV disease, degree of viral suppression, CD4 count at HAART initiation, gender, age, and duration of exposure to HAART. ${ }^{17,23-28}$ Visible changes in fat distribution appear early after the start of therapy, within 3 months to 1 year according to different studies, and can be progressive. ${ }^{18,25,26}$ Some nucleoside reverse transcriptase inhibitors (NRTIs), particularly thymidine analogues, have been strongly associated with lipodystrophy, especially lipoatrophy, but currently, most of the available classes of antiretroviral drugs have been found to be involved with the abnormal fat distribution in HIV patients. $^{29-33}$

Dermatologic disorders constitute another group of appearance-related side effects of HAART. Although their causes may be difficult to determine because HIV patients often take antiretrovirals in conjunction with other drugs, certain antiretroviral agents are associated with specific cutaneous manifestations. Skin rashes have been reported in association with abacavir, non-NRTIs, and some PIs. Skin and nail hyperpigmentation has been observed with emtricitabine and zidovudine use, and jaundice and conjunctival pigmentation secondary to hyperbilirubinemia are side effects observed with atazanavir and indinavir use..$^{14,34,35}$

Most of these antiretroviral-induced physical changes usually occur soon after the start of therapy and, with the exception of lipodystrophy, are usually reversible or treatable. Fat changes are not easily treatable, and might even cause chronic disfigurement and pain. ${ }^{36}$ Current strategies for the treatment of lipodystrophy involve regimen switching, for example NRTI sparing, and reconstructive-cosmetic techniques, such as facial lipofilling, which has shown promising results in the long-term treatment of this condition. ${ }^{14,37}$

Although much of current research has focused on those alterations that increase the risk of mortality, the development of appearance-related changes can be stigmatizing and socially distressful, producing a significant impact on quality of life (QOL), 38,39 which can lead to decreased adherence to therapy, suboptimal drug levels, and development of drug resistance. ${ }^{40,41}$ Moreover, a study demonstrated that HIVinfected patients were willing to trade length of life for the avoidance of appearance-related adverse drug effects. ${ }^{42}$

Given the importance of the timely recognition of body physical changes (BPC) caused by HAART, we sought to determine the prevalence of BPC as perceived by patients with HIV infection, and compared it to the prevalence of BPC as perceived by their treating physicians. Other objectives of this study were to compare the perception of the types of BPC perceived between patients and physicians, and the impact that BPC had on daily life according to gender.

\section{Patients and Methods}

\section{Study design}

This epidemiologic study consisted of a stratified multistage probabilistic survey to evaluate the prevalence of perceived BPC by HIV patients and their treating physicians. Patients were eligible to be included if they had documented HIV infection and were willing to participate in the study. The study protocol was approved by the Ethics Committee of Hospital Clínico San Carlos (Madrid), and an informed consent was obtained from all patients before they were included in the study.

\section{Study procedures}

Data were gathered throughout several health centers in Spain. The survey consisted of two parallel questionnaires designed specifically for this study, which were to be completed simultaneously, but independently, by the physician for a specific patient and by that particular patient during a single visit. Both questionnaires included an initial section where baseline patient characteristics were recorded, including age, gender, route of HIV infection, duration of HAART, route of infection and occupational status. Subsequently, patients and physicians were asked if they had noted the presence of BPC since the start of HAART; if the answer was "no," the questionnaire ended. If, on the other hand, the physician and/or the patient answered "yes," they proceeded to provide details about these changes, which included the perception of changes in skin and conjunctival pigmentation, and whether or not they had perceived fat loss in the face, upper and lower limbs and buttocks, or fat accumulation in the neck, lower back, chest, and trunk. In addition, patients and physicians were asked to provide a subjective rating of the severity of the fat loss or accumulation (mild, moderate or severe). Finally, physicians were asked for how long had they noticed the presence of BPC in their patients (less than 6 months ago, 6 to 12 months ago, or more than 12 months ago), and patients were asked if the presence of BPC had influenced in any way the following aspects of their daily life: mood, daily activities, personal relationships, and self-esteem.

Physical changes were defined as the perception of an increase (lipohypertrophy) or reduction (lipoatrophy) in bodily fat of whatever severity in at least one of the abovementioned body parts.

\section{Statistical analysis}

The primary objective of this study was to estimate the prevalence of BPC perceived by HIV-positive patients receiving HAART and their attending physicians, which had been previously estimated as greater than or equal to $25 \%$, with a relative error less than or equal to $10 \%$. Considering a finite population of 60,000 HIV-seropositive patients receiving HAART, and a design effect of $15 \%$, a sample size of 813 evaluable patients was calculated. In addition, taking into account a phenomenon of nonresponse, and lack of evaluability due to any cause, the sample size was increased in $20 \%$ to 1016 patients and rounded to 1020 . Secondary objectives were to compare the perception of BPC between patients and 
physicians, to compare the prevalence of BPC in men and women, and to determine whether subjective perceptions of its importance were gender-specific.

In order to perform a stratified, multistage study, 17 regions were grouped into 12 strata, and the number of patients and centers involved in each stratum was calculated according to the overall HIV population in the area, with an overall sampling fraction of $0.017(0.014-0.026)$. In the first stage, 102 health centers or hospitals were randomly selected with a probability proportional to the number of HIV patients followed up during the last year. In the second stage, attending physicians were selected by simple random sampling from each participating center. Finally, in the third stage, 10 patients from those scheduled by the physician during the study period (January 13 until March 18, 2008) were selected by systematic sampling to fill out the questionnaire. There was no reposition of patients who refused to participate in the study.

Qualitative variables are shown as absolute and relative frequencies, and adjusted percentages with $95 \%$ confidence interval $(\mathrm{CI})$ considering the entire study population overall or per gender. Impact on daily life was only assessed in patients (overall and per gender) who reported having perceived BPC. Continuous variables were described using mean and standard deviation. Degree of patient-physician agreement was measured using Cohen's $\kappa$. Comparison of percentages between independent groups was performed with the $\chi^{2}$ test, and within the same group with the McNemar test or generalized marginal homogeneity test. To study the association between BPC and duration of HAART treatment, quartiles of time under HAART were calculated and classified as follows: less than three years, from three to seven years, from seven to ten years, and more than ten years. Statistical analyses were carried out using SPSS v15.0 software (SPSS Inc., Chicago, IL). Statistical significance was set at $p<0.05$.

\section{Results}

\section{Description of participants}

Between January and February 2008, a total of 965 patientphysician questionnaires were collected across 98 health centers. Mean age of the patients was $43.7 \pm 8.5$ years. Seven hundred one patients surveyed $(72.6 \%)$ were men and 255 $(26.4 \%)$ women; gender was not reported in nine subjects. Nine hundred eight patients (94.1\%) acquired HIV infection through a single route, either through intravenous drug use $(39.0 \%)$, homosexual $(26.9 \%)$ or heterosexual contact $(25.9 \%)$. Mean time of HAART was $88.3 \pm 55.5$ months. Of the patients included in the study, $74.3 \%$ had received HAART for a period longer than three years, and $26.3 \%$ had received HAART for more than 10 years. Regarding occupational status, 627 $(65.0 \%)$ were currently employed, 85 pensioners or retired $(8.8 \%), 57$ unemployed (5.9\%), and 31 students (3.2\%). Details of baseline patient characteristics are shown in Table 1.

\section{Perception and severity of BPC by patients and physicians}

There was a concordance of $88.3 \%$ in the perception of BPC between physicians and their corresponding patients $(\kappa=0.682 ; p<0.0005)$; in other words, most physicians and patients agreed that they had developed BPC. On the con-
Table 1. Baseline Patient Characteristics $(\mathrm{n}=965)$

\begin{tabular}{|c|c|c|}
\hline Characteristics & $\mathrm{n}$ & $\%$ \\
\hline \multicolumn{3}{|l|}{ Age (years) } \\
\hline Mean $( \pm S D)$ & \multicolumn{2}{|c|}{$43.7( \pm 8.5)$} \\
\hline \multicolumn{3}{|l|}{ Gender } \\
\hline Male & 701 & 72.6 \\
\hline \multicolumn{3}{|l|}{ Route of infection } \\
\hline \multicolumn{3}{|l|}{ Single route of infection } \\
\hline IDU & 376 & 39.0 \\
\hline Homosexual contact & 260 & 26.9 \\
\hline Heterosexual contact & 250 & 25.9 \\
\hline Other & 22 & 2.3 \\
\hline \multicolumn{3}{|l|}{ Two routes of infection } \\
\hline Heterosexual contact + IDU & 12 & 1.2 \\
\hline Heterosexual contact + homosexual & 12 & 1.2 \\
\hline Homosexual contact + IDU & 4 & 0.5 \\
\hline Not reported & 29 & 3.0 \\
\hline Mean time of HAART (months) & \multicolumn{2}{|c|}{$88.3 \pm 55.5$} \\
\hline \multicolumn{3}{|l|}{ Duration of HAART (years) } \\
\hline$<3$ & 210 & 21.8 \\
\hline $3-7$ & 244 & 25.3 \\
\hline $7-10$ & 219 & 22.7 \\
\hline$>10$ & 254 & 26.3 \\
\hline Not reported & 38 & 3.9 \\
\hline \multicolumn{3}{|l|}{ Occupational status } \\
\hline Employed & 627 & 65.0 \\
\hline Pensioner/retired & 85 & 8.8 \\
\hline Unemployed & 57 & 5.9 \\
\hline Student & 31 & 3.2 \\
\hline Other & 141 & 14.6 \\
\hline Not reported & 24 & 2.5 \\
\hline
\end{tabular}

HAART, highly active antiretroviral therapy; IDU, intravenous drug use; SD, standard deviation.

trary, $7.7 \%$ of the patients considered they had not developed $\mathrm{BPC}$, while their treating physicians thought they had, and $7.8 \%$ of the patients perceived they had developed BPC, while their treating physicians thought they had not. More than half of the patients (55.1\%; 95\% CI: 52.0-58.1) perceived they had suffered BPC since they started receiving HAART; similarly, more than half of the physicians $(55.2 \%$; $95 \% \mathrm{CI}$ : 52.1-58.2) perceived their patients had developed BPC. No significant differences were detected between these percentages $(p=1.000)$. The most common BPC identified by patients and physicians was lipoatrophy, although it was mentioned by significantly more physicians (49.4\%; 95\% CI: 46.3-52.5\%) than patients (46.8\%; 95\% CI: 43.7-49.8\%; $p=0.033)$. The face was the body part most affected by lipoatrophy, followed closely by the lower limbs, buttocks and upper limbs. No significant differences were observed between patient and physician perceptions regarding the body part affected by lipoatrophy (Table 2). Lipohypertrophy was the next BPC most frequently noted by patients and also by physicians. The percentage of patients mentioning lipohypertrophy differed significantly from the percentage reported by physicians (28.7\% [95\% CI: $25.9-31.4$ ] versus $25.7 \%$ [95\% CI: $23.0-28.4]$; $p=0.032)$. The trunk was the body part most commonly affected by lipohypertrophy, perceived by $24.9 \%$ (95\% CI: $21.3-$ $28.5)$ of the patients and $22.8 \%$ (95\% CI: 19.3-26.2) of the physicians, followed by the chest, neck and lower back. There were no significant differences between frequencies observed 
Table 2. Comparison of Body Physical Changes Perceived by Patients and Physicians $(\mathrm{n}=965)$

\begin{tabular}{|c|c|c|c|c|c|c|c|}
\hline \multirow[b]{2}{*}{ Event } & \multicolumn{3}{|c|}{ Patients } & \multicolumn{3}{|c|}{ Physicians } & \multirow{2}{*}{$\frac{\text { McNemar's test }}{\mathrm{p}}$} \\
\hline & $\mathrm{n}$ & Adjusted \% & $95 \% \mathrm{CI}$ & $\mathrm{n}$ & Adjusted \% & $95 \% C I$ & \\
\hline Overall BPC & 539 & 55.1 & $52.0-58.1$ & 542 & 55.2 & $52.1-58.2$ & 1.000 \\
\hline Lipoatrophy & 456 & 46.8 & $43.7-49.8$ & 485 & 49.4 & $46.3-52.5$ & $0.033^{\mathrm{a}}$ \\
\hline Face & & 38.7 & $34.7-42.7$ & & 42.8 & $38.7-46.8$ & 0.417 \\
\hline Upper limbs & & 30.1 & $26.3-33.9$ & & 30.6 & $26.8-34.4$ & 0.551 \\
\hline Lower limbs & & 36.4 & $32.4-40.3$ & & 36.6 & $32.6-40.5$ & 0.868 \\
\hline Buttocks & & 35.1 & $31.2-39.1$ & & 34.8 & $30.9-38.8$ & 1.000 \\
\hline Lipohypertrophy & 280 & 28.7 & $25.9-31.4$ & 252 & 25.7 & $23.0-28.4$ & $0.032^{\mathrm{a}}$ \\
\hline Neck & & 9.0 & 6.7-11.4 & & 7.9 & 5.7-10.2 & 1.000 \\
\hline Lower back & & 7.0 & 4.9-9.1 & & 6.3 & $4.3-8.3$ & 0.735 \\
\hline Trunk & & 24.9 & $21.3-28.5$ & & 22.8 & $19.3-26.2$ & 1.000 \\
\hline Chest & & 8.9 & 6.6-11.3 & & 8.7 & 6.4-11.1 & 0.556 \\
\hline Skin pigmentation changes & 60 & 5.9 & $4.5-7.4$ & 24 & 2.4 & $1.4-3.3$ & $<0.0005^{\mathrm{a}}$ \\
\hline Conjunctival pigmentation & 38 & 3.9 & $2.7-5.1$ & 31 & 3.1 & $2.1-4.2$ & 0.230 \\
\hline
\end{tabular}

aStatistically significant $(p<0.05)$.

$\mathrm{BPC}$, body physical changes; $\mathrm{CI}$, confidence interval.

by patients and physicians (Table 2). Skin pigmentation changes were perceived significantly less often by physicians than by patients (2.4\% [95\% CI: $1.4-3.3$ ] versus 5.9\% [95\% CI: $4.5-7.4] ; p<0.0005)$. No significant differences were observed regarding conjunctival pigmentation, which was noted by $3.9 \%$ (95\% CI: $2.7-5.1)$ of patients and $3.1 \%$ (95\% CI: $2.1-4.2)$ of physicians (Table 2).

To the question "For how long have you noticed the presence of BPC on your patient," 79.2\% (95\% CI: 76.0-82.4) of the physicians answered they had noticed these changes for more than 1 year.

Regarding HAART duration, there was a significant association between the perception of BPC and the duration of HAART exposure $(p<0.0005)$. Overall, $19.8 \%$ (95\% CI: $16.4-$ 23.2) of patients on HAART for more than 10 years perceived BPC compared to $4.9 \%$ (95\% CI: 3.6-6.3) of patients who had been on HAART for less than 3 years. McNemar's test did not evidence significant differences between patients' and physicians' perception in any of the time of HAART exposure groups ( $<3$ years, $p=0.180 ; 3-7$ years, $p=0.072 ; 7-10$ years, $p=0.118$; and $>10$ years, $p=0.417$; Fig. 1$)$.
In relation to the severity of lipodystrophy-related BPC, most patients and physicians considered the changes to be mild or moderate, regardless of whether the BPC was lipoatrophy or lipohypertrophy, or of the body region affected (Table 3). The marginal homogeneity test only showed significant differences between the severity of lipohypertrophy affecting the trunk $(p=0.003)$ and the chest $(p=0.047)$, reported by patients and physicians, reflecting the similarity between patient's and physician's assessment of the perceived severity of BPC.

\section{Perception of BPC between men and women}

No significant differences were observed in the overall prevalence of BPC perceived by men (54.7\%; 95\% CI: 51.1-58.3) and women (56.9\%; 95\% CI: 50.8-63.0; $p=0.649$ ). However, regarding specific BPC, significantly more women reported lipoatrophy of the lower limbs (42.7\% versus $33.7 \%$; $p=0.009)$ and buttocks (41.5\% versus $32.3 \% ; p=0.007)$, as well as overall lipohypertrophy $(34.7 \%$ versus $26.5 \%$; $p=$ $0.007)$, than men. No significant differences were observed

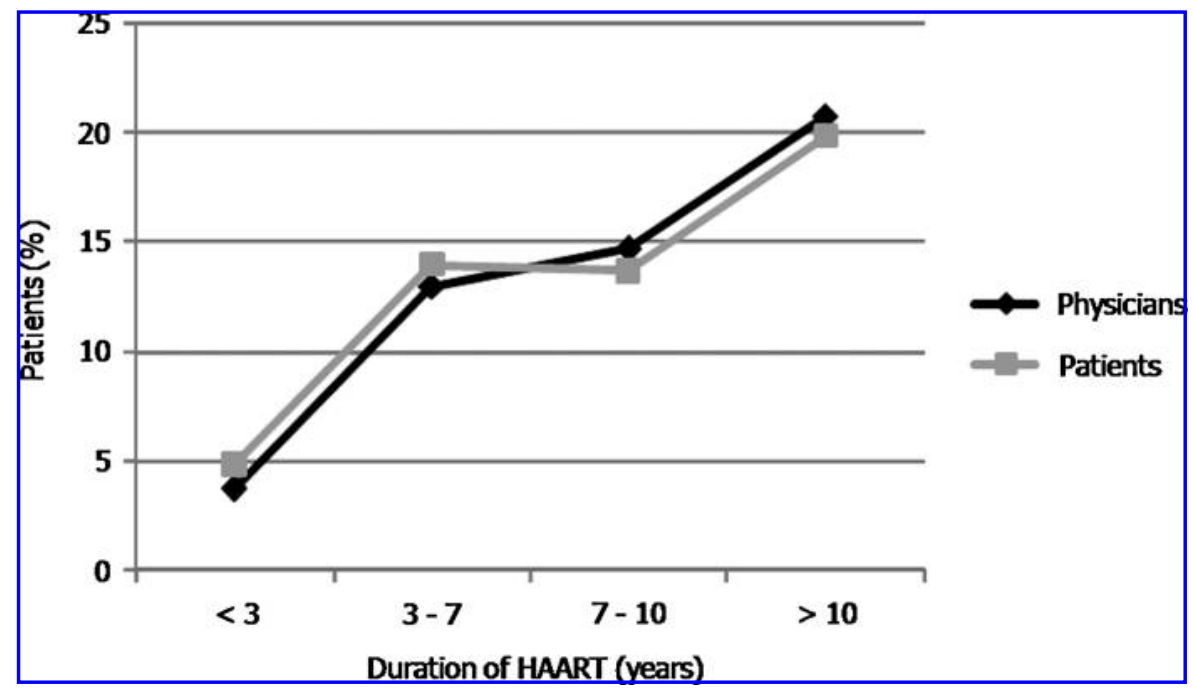

FIG. 1. Percentage of patients referring body physical changes (BPC) in relation to years of highly active antiretroviral therapy (HAART) duration $(n=965)$. 
Table 3. Severity of Lipoatrophy According to Patients and Physicians

\begin{tabular}{|c|c|c|c|c|c|c|c|c|}
\hline \multirow[b]{2}{*}{ Severity } & \multicolumn{4}{|c|}{ Lipoatrophy, n $(\%)^{\mathrm{a}}$} & \multicolumn{4}{|c|}{ Lipohypertrophy, n (\%) } \\
\hline & Face & Upper limbs & Lower limbs & Buttocks & Neck & Lower back & Trunk & Chest \\
\hline Patients & $n=381$ & $n=296$ & $n=358$ & $n=346$ & $n=89$ & $n=69$ & $n=245$ & $n=88$ \\
\hline Mild & $164(43.0)$ & 147 (49.7) & $132(36.9)$ & $130(37.6)$ & $43(48,3)$ & $47(68.1)$ & $104(42.4)$ & $51(57.9)$ \\
\hline Moderate & $131(34.4)$ & $103(34.8)$ & $145(40.5)$ & $119(34.4)$ & $21(23.6)$ & $14(20.3)$ & 92 (37.6) & $21(23.9)$ \\
\hline Severe & $86(22.6)$ & 46 (15.5) & $81(22.6)$ & $97(28.0)$ & $25(28.1)$ & $8(11.6)$ & $49(20.0)$ & $16(18.2)$ \\
\hline Physicians & $n=421$ & $n=301$ & $n=360$ & $n=343$ & $n=78$ & $n=62$ & $n=224$ & $n=86$ \\
\hline Mild & 189 (44.9) & 144 (47.8) & 132 (36.7) & 118 (34.4) & $31(39.8)$ & 45 (72.6) & $86(38.4)$ & 46 (53.5) \\
\hline Moderate & 158 (37.5) & 132 (43.9) & 179 (49.7) & $166(48.4)$ & $26(33.3)$ & $15(24.2)$ & $119(53.1)$ & $37(43.0)$ \\
\hline Severe & 74 (17.6) & $25(8.3)$ & 49 (13.6) & $59(17.2)$ & $21(26.9)$ & $2(3.2)$ & $19(8.5)$ & $3(3.5)$ \\
\hline GMHT $p$ value & 0.828 & 0.227 & 0.655 & 0.169 & 0.633 & 0.204 & $0.003^{b}$ & $0.047^{\mathrm{b}}$ \\
\hline
\end{tabular}

${ }^{a}$ Percentage of severity grade declared by patients and/or physicians reporting each event.

${ }^{\mathrm{b}}$ Statistically significant $(p<0.05)$.

GHMT, Generalized marginal homogeneity test.

between changes perceived by men and women regarding skin pigmentation changes and conjunctival pigmentation (Table 4).

\section{Impact of BPC on daily life}

Three-hundred twenty-four patients $(58.2 \%$ of those reporting BPC; 95\% CI: 54.0-62.4) noted that the development of BPC negatively affected their daily life. When divided according to gender, $63.4 \%$ (95\% CI: 56.3-70.5) of women and $56.1 \%$ (95\% CI: 51.2-61.1) of men mentioned that BPC had an impact on their daily life overall, without significant differences between genders $(p=0.209)$. Additionally, as for the effect of BPC on specific aspects of daily life, significantly more women described mood changes $(53.0 \%$; 95\% CI: $45.6-$ $60.4)$ compared to men (31.5\%; 95\% CI: $26.8-45.6 ; p<0.0005)$. Also, significantly more women (32.2\%; 95\% CI: 24.9-39.5) noted that BPC affected their self esteem than men $(23.2 \%$; 95\% CI: 19.1-27.4; $p=0.030$ ), whereas the effects of BPC on daily activities and personal relationships noticed by men and women were not significantly different $(p=0.2244$ and $p=0.355$, respectively; Fig. 2).

\section{Discussion}

The results of our study demonstrate that BPC perceived by $\mathrm{HIV}$-infected patients as well as by their treating physicians is highly prevalent. In fact, the estimated prevalence of perceived BPC doubled the initial statistical estimation of $25 \%$, underscoring the significance of our findings. The most common BPC described by patients and physicians was lipoatrophy, with estimated prevalence rates of $46.8 \%$ and $49.4 \%$, respectively. Lipohypertrophy was the next BPC most reported by patients and physicians, with prevalence rates of $28.7 \%$ and $25.7 \%$, respectively. In relation to lipodystrophy as a whole, although studies have yielded variable results, ${ }^{21,41,43-47}$ those including a similar sample size as the one used in our study reported prevalence rates of lipodystrophy perceived by HIV-infected patients that range between $28 \%$ and $49 \% .{ }^{43,47}$ The reason behind these differences might be the lack of an objective definition and measurement of lipodystrophy, ${ }^{21}$ and the presence of confounding factors such as age, gender, and type and duration of HAART. ${ }^{22}$

When patients and physicians were asked to grade the severity of lipodystrophic changes, all of them were regarded,

Table 4. Comparison of Body Physical Changes Perceived by Men and Women $(\mathrm{n}=956)^{\mathrm{a}}$

\begin{tabular}{|c|c|c|c|c|c|c|c|}
\hline \multirow[b]{2}{*}{ Event } & \multicolumn{3}{|c|}{$\operatorname{Men}(\mathrm{n}=701)$} & \multicolumn{3}{|c|}{ Women $(\mathrm{n}=255)$} & \multirow{2}{*}{$\begin{array}{c}\text { McNemar's test } \\
\mathrm{p}\end{array}$} \\
\hline & $\mathrm{n}$ & Adjusted \% & $95 \% C I$ & $\mathrm{n}$ & Adjusted \% & $95 \% \mathrm{CI}$ & \\
\hline Overall BPC & 387 & 54.7 & $51.1-58.3$ & 145 & 56.9 & $50.8-63.0$ & 0.649 \\
\hline Lipoatrophy & 321 & 45.7 & $42.1-49.3$ & 128 & 50.5 & $44.4-56.6$ & 0.228 \\
\hline Face & & 38.2 & $34.2-42.2$ & & 39.2 & $35.2-43.2$ & 0.768 \\
\hline Upper limbs & & 28.5 & $24.8-32.3$ & & 34.2 & $30.3-38.1$ & 0.085 \\
\hline Lower limbs & & 33.7 & $29.8-37.6$ & & 42.7 & $38.6-46.7$ & $0.009^{b}$ \\
\hline Buttocks & & 32.3 & $28.4-36.2$ & & 41.5 & $37.4-45.6$ & $0.007^{\mathrm{b}}$ \\
\hline Lipohypertrophy & 188 & 26.5 & $23.3-29.8$ & 88 & 34.7 & $28.6-40.7$ & $0.007^{\mathrm{b}}$ \\
\hline Neck & & 8.4 & $6.1-10.7$ & & 10.4 & $7.8-12.9$ & 0.335 \\
\hline Lower back & & 6.3 & $4.3-8.3$ & & 17.3 & $14.2-20.4$ & $<0.0005^{\mathrm{b}}$ \\
\hline Abdomen & & 22.7 & $19.2-26.1$ & & 30.7 & $26.9-34.6$ & $0.001^{\mathrm{b}}$ \\
\hline Chest & & 7.0 & $4.9-9.1$ & & 14.6 & $11.7-17.5$ & $<0.0005^{\mathrm{b}}$ \\
\hline Skin pigmentation changes & 40 & 5.6 & $3.9-7.3$ & 19 & 6.8 & $3.8-9.8$ & 0.321 \\
\hline Conjunctival pigmentation & 27 & 3.7 & $2.3-5.1$ & 10 & 3.8 & $1.4-6.1$ & 0.960 \\
\hline
\end{tabular}

${ }^{a}$ Gender was not reported in 9 subjects.

${ }^{\mathrm{b}}$ Statistically significant $(p<0.05)$.

BPC, body physical changes; CI, confidence interval. 


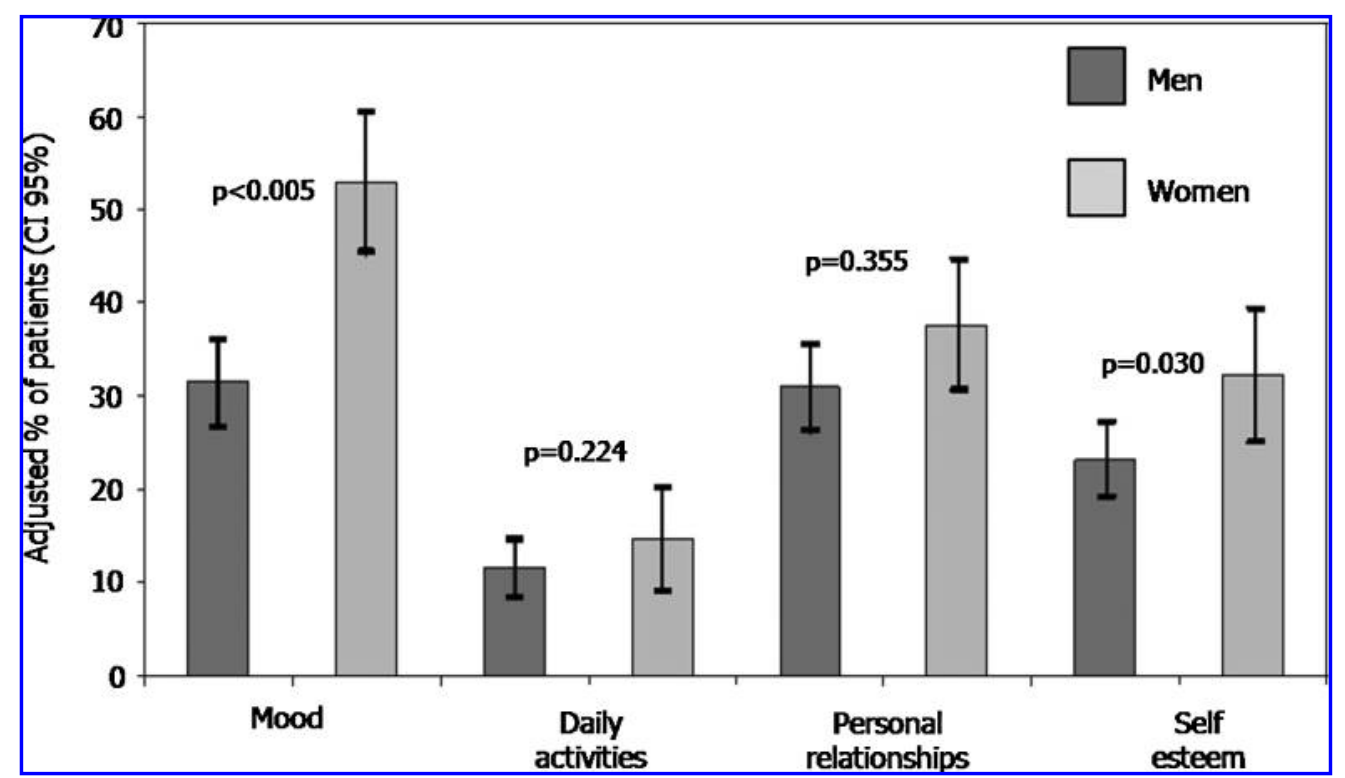

FIG. 2. Impact of body physical changes on daily life among men and women reporting body physical changes (BPC).

for the most part, as mild or moderate. Lipodystrophy is a complex syndrome, and its etiology is far from understood, ${ }^{17}$ and so its treatment is equally complex. Antiretroviral switching has been rigorously studied and, although results on improvement of lipohypertrophy are confusing or even contradictory, ${ }^{48}$ current data on improvement of lipoatrophy indicate that switching to less toxic NRTIs (e.g., avoiding thymidine analogue NRTIs) such as abacavir or tenofovir leads to a limb fat gain, but this fat improvement is slow and incomplete. ${ }^{49-51}$ Thus, given the difficulty of reverting lipodystrophic changes, and since there are less toxic therapeutic options available, it seems reasonable to prevent the development of this disorder at its earliest and less severe stages than to wait until it becomes clinically evident.

In our study, significantly more patients perceived skin pigmentation changes than physicians. Some of the reasons behind this might be that dermatological conditions are less evident than other BPC, and hence are perceived less frequently by the attending physician. On the other hand, conjunctival pigmentation was perceived by almost as many patients as physicians. Jaundice and conjunctival pigmentation, a consequence of hyperbilirubinemia, is a side effect developed by approximately $30 \%$ of patients taking the PI atazanavir. $^{52}$ Although these signs are reversible upon discontinuation, and elevations in unconjugated bilirubin do not seem to produce other significant side effects besides those related to appearance, ${ }^{52}$ the presence of jaundice may lead to esthetic concerns and social distress.

One of the objectives of this study was to investigate the impact that the development of BPC has on daily life of HIVinfected patients. Given the high prevalence of BPC found in our study population, this matter is worth considering. Our results showed that more than half $(58.2 \%)$ of the patients reporting BPC thought that these affected their daily life; this effect seemed to be greater within the female population, and significantly greater for mood and self-esteem implications with respect to men. Although few studies have assessed this issue, those that have done so agree that appearance-related changes do have a significant impact on daily life in HIVinfected patients. ${ }^{39}$ The development of lipodystrophy in HIV-infected patients produces feelings of shame, influences choice of clothing, disrupts sex life, impairs psychosocial functioning and generates bodily discomfort, low self-esteem and depression. ${ }^{38,53}$ In addition, patients with lipodystrophy often feel they can be recognized as HIV positive by their physical appearance, ${ }^{46}$ a reminder of the early years of AIDS when BPC developed by HIV-infected patients were recognized as true landmarks of the disease. Our results confirm these observations, as lipodystrophy had a negative effect on body image perception and self-esteem, which could eventually lead to stigmatization of interpersonal and intimate relations, as has been demonstrated by other authors. ${ }^{44,54,55}$ Above all, several studies have proven that the negative effects that BPC have on daily life are an important source of reduced adherence to therapy, ${ }^{40,41,56}$ particularly in patientperceived BPC in comparison to clinically diagnosed BPC. ${ }^{57}$

We acknowledge that the results of this observational study should be interpreted in the light of potential limitations inherent in epidemiologic studies; also, the use of validated health-related quality of life questionnaires could have been helpful to determine with certainty whether HIVinfected patients with BPC have a worse quality of life and functionality than patients without BPC. Nevertheless, our study provides significant data on BPC prevalence in the HIV population on HAART in our country, which had not been previously estimated. Furthermore, we consider this study is of special relevance due to the lack of trials assessing daily life in HIV-infected patients, and the growing interest in the wellbeing of patients with this disease in the HAART era. Thus, based on these two main outcomes, it is of special importance that physicians treating HIV subjects actively search for BPC and ask their patients about the impact of BPC on their daily lives.

Finally, health professionals should be aware of the psychosocial consequences of BPC in HIV patients in order to reduce potential negative effects on therapy, such as reduced 
adherence to HAART. A reasonable strategy would be to start therapy early with a regimen not associated with lipodystrophy, or to switch to less toxic antiretrovirals as they become available.

\section{Acknowledgments}

The authors acknowledge Dr. Jesús Garrido for the statistical analysis of the study and Dr. Ximena Alvira from HealthCo SL (Madrid, Spain) for assistance in the preparation of this manuscript. Participation of the following investigators belonging to the HIV Body Physical Changes Study Group is gratefully acknowledged:

\section{HIV Body Physical Changes Study Group Members:}

Andalucía: Dolores Merino (H. Juan Ramón Jiménez, Huelva); Valme Sánchez, Leopoldo Muñoz Medina (H. Univ. San Cecilio, Granada); Carmen Hidalgo (H. Univ. Virgen de las Nieves, Granada); Carmen Gálvez (H. Torrecárdenas, Almería); Eugenio Pérez Guzmán (H. Univ. Puerta del Mar, Cádiz); Fernando Lozano (H. Ntra. Sra. de Valme, Sevilla); $M^{a}$ José Ríos Villegas (H. Univ. Virgen Macarena, Sevilla); Ángela Camacho (H. Univ. Reina Sofía, Córdoba); Manuel Márquez (H. Univ. Virgen de la Victoria, Málaga); Manuel Castaño, Francisco Jiménez Oñate ( $\mathrm{H}$. Carlos Haya, Málaga); Inmaculada Rivas, Rosario Mata (H. Univ. Virgen del Rocío, Sevilla); Francisco Téllez (H. de la Línea, La Línea, Cádiz).

Aragón: $\mathrm{M}^{\mathrm{a}}$ José Crusells (H. Clin. Univ. Zaragoza, Zaragoza); Ascensión Pascual (H. Miguel Servet, Zaragoza).

Asturias: Miguel de Zárraga (H. San Agustín, Avilés); Jose A. Cartón (H. Central de Asturias, Oviedo).

Baleares: Francisco Homar (H. Fund. Sont Llatzer, Palma de Mallorca); Javier Murillas, Concepción Villalonga ( $\mathrm{H}$. Univ. Son Dureta, Palma de Mallorca).

Canarias: Michelle Hernández (H. Univ. Insular de Gran Canaria, Las Palmas); Remedios Alemán (Consorcio sanitario de Tenerife, Tenerife); Marcelino Hayek ( $\mathrm{H}$. Ntra. Sra. de la Candelaria, Tenerife); Miguel A. Cárdenes (H. de Gran Canaria Doctor Negrín, Las Palmas).

Castilla-León: Francisco Vega (H. del Bierzo, Ponferrada); Pablo Bachiller (H. Río Ortega, Valladolid); Miguel A. del Pozo (H. Clin. Univ. de Valladolid, Valladolid).

Cataluña: Angels Massabe (H. de Palamós, Palamós, Gerona); Silvia Valero (H. Sant Jaume, Calella, Barcelona); Cristina Cortés, Isabel García, Patricia N. Barragán, Montserrat Olmo, María Saurroy (H. Príncipes de Espanya de L'Hospitalet, Hospitalet de Llobregat, Barcelona); Xavier Martínez (H. Mútua de Tarrasa, Tarrasa, Barcelona); Carlos Alonso Villaverde (H. Sant Joan, Reus, Tarragona); Teresa Puig (H. Univ. Arnau de Vilanova, Lleida); Montserrat Sala, Manuel Cervantes (Corporació Parc Taulí, Barcelona), Mar Gutiérrez, Pere Domingo (H. Univ. de la Santa Creu i Sant Pau, Barcelona); Gabriel Vallecillo, Ana Guelar (H. Gral. Ntra. Sra. del Mar, Barcelona); Adriá Currà, Vicenc Falcó (H. de Vall d’Hebrón, Barcelona); María Martínez, María Larousse, Anna Milinkovic (H. Clínic i Provincial, Barcelona); Patricia Echevarría, Jose R. Santos, Anna Bonjoch (H. Germans Trias i Pujol, Badalona, Barcelona).

Extremadura: Carlos Martín Ruiz (H. Ntra. Sra. de la Montaña, Cáceres).

Galicia: Elena Losada, Antonio Antela, Arturo Prieto (H. Clin. Univ. de Santiago, Santiago de Compostela); Ana Mar- iño (H. Arquitecto Marcide, El Ferrol, A Coruña); Rafael Ojea de Castro (Complejo Hosp. de Pontevedra, Pontevedra); Soledad López Calvo (H. Juan Canalejo - A Coruña); Celia Miralles (H. Xeral Cíes, Vigo, Pontevedra).

La Rioja: Jose Ramón Blanco (Complejo Hosp. San MillánSan Pedro, Logroño).

Madrid: Gabriel Gaspar (H. Univ. Getafe, Getafe); Teodoro Martín (Clínica Puerta de Hierro, Madrid); José Sanz (H. Univ. Príncipes de Asturias, Alcalá de Henares, Madrid); Ana Goyenechea (Fundación Jiménez Díaz, Madrid); Carlos Barros (H. Gral. De Móstoles, Móstoles, Madrid); Ignacio de los Santos, Jesús Sanz (H. Univ. de La Princesa, Madrid); Jorge Vergas, Vicente Estrada, $\mathrm{M}^{\mathrm{a}}$ Jesús Téllez, (H. Clin. San Carlos, Madrid); Pablo Labarga, Victoria Moreno (H. Carlos III, Madrid); Rafael Torres, Juan José Jusdado (H. Severo Ochoa, Leganés, Madrid); Ana Moreno, Jose L. Casado, $\mathrm{M}^{\mathrm{a}}$ Jesús Pérez-Elías (H. Univ. Ramón y Cajal, Madrid); Juan C. López, Pilar Miralles, Juan Berenguer (H. Gral. Gregorio Marañón, Madrid).

Murcia: Carlos Galera (H. Univ. Vgen. de la Arrixaca, Murcia); José A. García Henarejos (H. Sta. María del Rosell, Cartagena).

Navarra: Julio Sola (H. Provinvial de Navarra, Pamplona).

País Vasco: Eduardo Martínez, M ${ }^{a}$ Asunción García (H. de Galdakao, Galdakao, Vizcaya); Francisco Rodríguez Arrondo, Miguel A Von Wichmann (H. de Donosti, San Sebastián); Josefa Muñoz, Oscar L Ferrero Beneitez (H. Civil de Basurto, Bilbao); Anne Josune Goicoechea Aguirre (H. de Cruces, Bilbao).

Comunidad Valenciana: Joan G. Colomé (H. de la Vega Baja, Orihuela, Alicante); Félix Gutiérrez (H. Gral. Univ. de Elche, Elche, Alicante); Bernardino Roca ( $\mathrm{H}$. Gral. De Castellón, Castellón); Juan Flores (H. Arrnau de Vilanova, Valencia); Carmen Ricart, Jorge Carmena (H. Doctor Peset, Valencia); Federico Alcacer (H. Clin. Univ de Valencia, Valencia); Vicente Abril (H. Gral. de Valencia, Valencia); José Lacruz, José López Aldeguer (H. Univ. La Fe, Valencia).

\section{Author Disclosure Statement}

No competing financial interests exist.

\section{References}

1. Grunfeld C, Kotler DP. Pathophysiology of the AIDS wasting syndrome. AIDS Clin Rev 1992:191-224.

2. Coodley GO, Loveless MO, Merrill TM. The HIV wasting syndrome: A review. J Acquir Immune Defic Syndr 1994;7: 681-694.

3. Matis WL, Triana A, Shapiro R, et al. Dermatologic findings associated with human immunodeficiency virus infection. J Am Acad Dermatol 1987;17:746-751.

4. Macher AM. The pathology of AIDS. Public Health Rep 1988;103:246-254.

5. Kaplan MH, Sadick N, McNutt NS, et al. Dermatologic findings and manifestations of acquired immunodeficiency syndrome (AIDS). J Am Acad Dermatol 1987;16:485-506.

6. Maas JJ, Dukers N, Krol A, et al. Body mass index course in asymptomatic HIV-infected homosexual men and the predictive value of a decrease of body mass index for progression to AIDS. J Acquir Immune Defic Syndr Hum Retrovirol 1998;19:254-259.

7. Smith KJ, Skelton HG, Yeager J, et al. Cutaneous findings in HIV-1-positive patients: A 42-month prospective study. 
Military Medical Consortium for the Advancement of Retroviral Research (MMCARR). J Am Acad Dermatol 1994;31: 746-M54.

8. Panos G, Samonis G, Alexiou VG, et al. Mortality and morbidity of HIV infected patients receiving HAART: A cohort study. Curr HIV Res 2008;6:257-260.

9. Palella FJ, Jr., Baker RK, Moorman AC, et al. Mortality in the highly active antiretroviral therapy era: Changing causes of death and disease in the HIV outpatient study. I Acquir Immune Defic Syndr 2006;43:27-34.

10. Carr A, Samaras K, Burton S, et al. A syndrome of peripheral lipodystrophy, hyperlipidaemia and insulin resistance in patients receiving HIV protease inhibitors. AIDS 1998;12: F51-58.

11. Gerrior J, Kantaros J, Coakley E, Albrecht M, Wanke C. The fat redistribution syndrome in patients infected with HIV: Measurements of body shape abnormalities. I Am Diet Assoc 2001;101:1175-1180.

12. Madge S, Kinloch-de-Loes S, Mercey D, Johnson MA, Weller IV. Lipodystrophy in patients naive to HIV protease inhibitors. AIDS 1999;13:735-737.

13. Tien PC, Barron Y, Justman JE, et al. Antiretroviral therapies associated with lipoatrophy in HIV-infected women. AIDS Patient Care STDs 2007;21:297-305.

14. Hawkins T. Appearance-related side effects of HIV-1 treatment. AIDS Patient Care STDs 2006;20:6-18.

15. Moyle G. Metabolic issues associated with protease inhibitors. J Acquir Immune Defic Syndr 2007;45(Suppl 1):S19-26.

16. Samaras K, Wand H, Law M, et al. Prevalence of metabolic syndrome in HIV-infected patients receiving highly active antiretroviral therapy using International Diabetes Foundation and Adult Treatment Panel III criteria: Associations with insulin resistance, disturbed body fat compartmentalization, elevated C-reactive protein, and [corrected] hypoadiponectinemia. Diabetes Care 2007;30:113-119.

17. Wierzbicki AS, Purdon SD, Hardman TC, Kulasegaram R, Peters BS. HIV lipodystrophy and its metabolic consequences: Implications for clinical practice. Curr Med Res Opin 2008;24:609-624.

18. Carr A, Samaras K, Chisholm DJ, Cooper DA. Abnormal fat distribution and use of protease inhibitors. Lancet 1998;351: 1736.

19. Carr A, Cooper DA. Adverse effects of antiretroviral therapy. Lancet 2000;356:1423-1430.

20. Chen D, Misra A, Garg A. Clinical review 153: Lipodystrophy in human immunodeficiency virus-infected patients. J Clin Endocrinol Metab 2002;87:4845-4856.

21. Carter VM, Hoy JF, Bailey M, et al. The prevalence of lipodystrophy in an ambulant HIV-infected population: It all depends on the definition. HIV Med 2001;2:174-180.

22. Carr A. HIV lipodystrophy: Risk factors, pathogenesis, diagnosis and management. Aids 2003;17(Suppl 1):S141-148.

23. Lichtenstein KA, Delaney KM, Armon C, et al. Incidence of and risk factors for lipoatrophy (abnormal fat loss) in ambulatory HIV-1-infected patients. I Acquir Immune Defic Syndr 2003;32:48-56.

24. Wohl DA, McComsey G, Tebas P, et al. Current concepts in the diagnosis and management of metabolic complications of HIV infection and its therapy. Clin Infect Dis 2006;43:645653.

25. Young J, Rickenbach M, Weber R, et al. Body fat changes among antiretroviral-naive patients on PI- and NNRTIbased HAART in the Swiss HIV cohort study. Antivir Ther 2005;10:73-81.
26. Martínez E, Mocroft A, García-Viejo MA, et al. Risk of lipodystrophy in HIV-1-infected patients treated with protease inhibitors: A prospective cohort study. Lancet 2001;357:592598.

27. Dube MP, Komarow L, Mulligan K, et al. Long-term body fat outcomes in antiretroviral-naive participants randomized to nelfinavir or efavirenz or both plus dual nucleosides. Dual X-ray absorptiometry results from A5005s, a substudy of Adult Clinical Trials Group 384. I Acquir Immune Defic Syndr 2007;45:508-514.

28. Haubrich RH, Riddler SA, DiRienzo AG, et al. Metabolic outcomes in a randomized trial of nucleoside, nonnucleoside and protease inhibitor-sparing regimens for initial HIV treatment. AIDS 2009;23:1109-1118.

29. Mallal SA, John M, Moore CB, James IR, McKinnon EJ. Contribution of nucleoside analogue reverse transcriptase inhibitors to subcutaneous fat wasting in patients with HIV infection. AIDS 2000;14:1309-1316.

30. van der Valk M, Gisolf EH, Reiss P, et al. Increased risk of lipodystrophy when nucleoside analogue reverse transcriptase inhibitors are included with protease inhibitors in the treatment of HIV-1 infection. AIDS 2001;15:847-855.

31. Gallant JE, Staszewski S, Pozniak AL, et al. Efficacy and safety of tenofovir DF vs stavudine in combination therapy in antiretroviral-naive patients: A 3-year randomized trial. JAMA 2004;292:191-201.

32. Seminari E, Tinelli C, Minoli L, et al. Evaluation of the risk factors associated with lipodystrophy development in a cohort of HIV-positive patients. Antivir Ther 2002;7:175-180.

33. Viganò A, Brambilla P, Cafarelli L, et al. Normalization of fat accrual in lipoatrophic, HIV-infected children switched from stavudine to tenofovir and from protease inhibitor to efavirenz. Antivir Ther 2007;12:297-302.

34. Luther J, Glesby MJ. Dermatologic adverse effects of antiretroviral therapy: Recognition and management. Am J Clin Dermatol 2007;8:221-233.

35. Kong HH, Myers SA. Cutaneous effects of highly active antiretroviral therapy in HIV-infected patients. Dermatol Ther 2005;18:58-66.

36. Phillips DR, Hay P. Current perspectives on the management and prevention of antiretroviral-associated lipoatrophy. I Antimicrob Chemother 2008;62:866-871.

37. Orlando G, Guaraldi G, De Fazio D, et al. Long-term psychometric outcomes of facial lipoatrophy therapy: Fortyeight-week observational, nonrandomized study. AIDS Patient Care STDs 2007;21:833-842.

38. Power R, Tate HL, McGill SM, Taylor C. A qualitative study of the psychosocial implications of lipodystrophy syndrome on HIV positive individuals. Sex Transm Infect 2003;79:137141.

39. Guaraldi G, Murri R, Orlando G, et al. Severity of lipodystrophy is associated with decreased health-related quality of life. AIDS Patient Care STDS 2008;22:577-585.

40. Ammassari A, Murri R, Pezzotti P, et al. Self-reported symptoms and medication side effects influence adherence to highly active antiretroviral therapy in persons with HIV infection. J Acquir Immune Defic Syndr 2001;28:445-449.

41. Duran S, Saves M, Spire B, et al. Failure to maintain longterm adherence to highly active antiretroviral therapy: The role of lipodystrophy. AIDS 2001;15:2441-2444.

42. Lenert LA, Feddersen M, Sturley A, Lee D. Adverse effects of medications and trade-offs between length of life and quality of life in human immunodeficiency virus infection. Am J Med 2002;113:229-232. 
43. Miller J, Carr A, Emery S, et al. HIV lipodystrophy: Prevalence, severity and correlates of risk in Australia. HIV Med 2003;4:293-301.

44. Santos CP, Felipe YX, Braga PE, et al. Self-perception of body changes in persons living with HIV/AIDS: Prevalence and associated factors. AIDS 2005;19(Suppl 4):S14-21.

45. Dreezen $C$, Schrooten $\bar{W}$, de Mey I, et al. Self-reported signs of lipodystrophy by persons living with HIV infection. Int J STD AIDS 2002;13:393-398.

46. Oette M, Juretzko P, Kroidl A, et al. Lipodystrophy syndrome and self-assessment of well-being and physical appearance in HIV-positive patients. AIDS Patient Care STDs 2002;16:413-417.

47. Lichtenstein K, Armon C, Buchacz K, et al. Early, Uninterrupted ART Is associated with improved outcomes and fewer toxicities in the HIV Outpatient Study (HOPS) [Poster \#769]. 13th Conference on Retroviruses and Opportunistic Infections. Denver, CO: February 2006.

48. Wohl DA, Brown TT. Management of morphologic changes associated with antiretroviral use in HIV-infected patients. I Acquir Immune Defic Syndr 2008;49(Suppl 2):S93-S100.

49. McComsey GA, Ward DJ, Hessenthaler SM, et al. Improvement in lipoatrophy associated with highly active antiretroviral therapy in human immunodeficiency virus-infected patients switched from stavudine to abacavir or zidovudine: The results of the TARHEEL study. Clin Infect Dis 2004; 38:263-270.

50. Moyle GJ, Sabin CA, Cartledge J, et al. A randomized comparative trial of tenofovir DF or abacavir as replacement for a thymidine analogue in persons with lipoatrophy. AIDS 2006;20:2043-2050.

51. Nguyen A, Calmy A, Schiffer V, et al. Lipodystrophy and weight changes: Data from the Swiss HIV Cohort Study, 2000-2006. HIV Med 2008;9:142-150.
52. Squires K, Lazzarin A, Gatell JM, et al. Comparison of oncedaily atazanavir with efavirenz, each in combination with fixed-dose zidovudine and lamivudine, as initial therapy for patients infected with HIV. J Acquir Immune Defic Syndr 2004;36:1011-1019.

53. Blanch J, Rousaud A, Martinez E, et al. Factors associated with severe impact of lipodystrophy on the quality of life of patients infected with HIV-1. Clin Infect Dis 2004;38:14641470.

54. Collins E, Wagner C, Walmsley S. Psychosocial impact of the lipodystrophy syndrome in HIV infection. AIDS Read 2000; 10:546-550.

55. Luzi K, Guaraldi G, Murri R, et al. Body image is a major determinant of sexual dysfunction in stable HIV-infected women. Antivir Ther 2009;14:85-92.

56. d'Arminio Monforte A, Lepri AC, Rezza G, et al. Insights into the reasons for discontinuation of the first highly active antiretroviral therapy (HAART) regimen in a cohort of antiretroviral naive patients. I.CO.N.A. Study Group. Italian Cohort of Antiretroviral-Naive Patients. AIDS 2000;14:499-507.

57. Ammassari A, Antinori A, Cozzi-Lepri A, et al. Relationship between HAART adherence and adipose tissue alterations. J Acquir Immune Defic Syndr 2002;31(Suppl 3):S140-144.

Address correspondence to: Esther Cabrero, Ph.D. Medical Department Abbott Laboratories, S.A. Avenida de Burgos, 91 28050-Madrid Spain

E-mail: esther.cabrero@abbott.com 
